\title{
Interaction of Some Commercial Teas with Some Carbohydrate Metabolizing Enzymes Linked with Type-2 Diabetes: A Dietary Intervention in the Prevention of Type-2 Diabetes
}

\author{
Ganiyu Oboh, ${ }^{1}$ Omodesola O. Ogunruku, ${ }^{1,2}$ Funke O. Ogidiolu, ${ }^{1}$ Adedayo O. Ademiluyi, \\ Bukola C. Adedayo, ${ }^{1}$ and Ayokunle O. Ademosun ${ }^{1}$ \\ ${ }^{1}$ Functional Foods and Nutraceuticals Unit, Biochemistry Department, Federal University of Technology, PMB 704, Akure, Nigeria \\ ${ }^{2}$ Biochemistry Department, Obafemi Awolowo University, Ile-Ife, Nigeria
}

Correspondence should be addressed to Ganiyu Oboh; goboh2001@yahoo.com

Received 25 November 2013; Accepted 13 December 2013; Published 16 January 2014

Academic Editor: Magdalena Gherardi

Copyright (C) 2014 Ganiyu Oboh et al. This is an open access article distributed under the Creative Commons Attribution License, which permits unrestricted use, distribution, and reproduction in any medium, provided the original work is properly cited.

\begin{abstract}
This study is aimed at assessing the inhibitory effect of teas on key enzymes ( $\alpha$-amylase and $\alpha$-glucosidase) linked with type2 diabetes and their antioxidant properties. Four samples of three brands were used; infusions of green tea (GT), 2 brands of black tea (BT), and a formulated herbal preparation for diabetes (ADT) (white tea, Radix Puerariae, Radix ophiopogonis, hawthorn berry, Chinese yam, and fragrant Solomon seal rhizome) were prepared and subsequently analyzed for their total phenol, ascorbic acid contents, antioxidant properties (2,2-Azizobis (3-Ethylbenzo-Thiazoline 6-sulfonate) "ABTS" scavenging ability and ferric reducing antioxidant property), and inhibition of pancreatic- $\alpha$-amylase and intestinal- $\alpha$-glucosidase in vitro. The study revealed that GT had the highest total phenol content, ascorbic acid content, ABTS* scavenging ability, and ferric reducing ability. Furthermore, all the teas inhibited $\mathrm{Fe}^{2+}$ and sodium nitroprusside induced lipid peroxidation in pancreas, with GT having the highest inhibitory effect. Conversely, there was no significant difference $(P>0.05)$ in the inhibitory effects of the teas on $\alpha$-amylase and $\alpha$-glucosidase. The antidiabetic property of the teas could be attributed to their inhibitory effect on carbohydrate hydrolyzing enzymes implicated in diabetes and their antioxidant activities.
\end{abstract}

\section{Introduction}

Diabetes mellitus (DM) is undoubtedly one of the most challenging health problems in the 21st century; statistics show that at 2011, 366 million people are suffering from DM, a figure expected to increase to 552 million people by 2030 [1]. DM is characterized by hyperglycemia associated with abnormal metabolism of carbohydrates, fats, and proteins resulting from endocrine defects in insulin action, secretion, or both [2]. The inhibition of alpha-amylase and alphaglucosidase, carbohydrate hydrolyzing enzymes, can significantly reduce postprandial hyperglycemia and are thus considered an important therapeutic strategy in the management of blood glucose level in type-2 diabetes [3]. Inhibition of these enzymes delays the breakdown of polysaccharides and glucose absorption, thereby reducing the amount of glucose in the blood [4]. In recent times, there has been a growing interest in medicinal plants and functional foods and their disease modulatory effects.

Tea (Camellia sinensis) is the most consumed beverage in the world next to water, its consumption far exceeding beer, wine, and soft drink [5]. Teas are differentiated based on the manufacturing (fermentation) process: green tea (GT)unfermented and black tea (BT)-fermented $[5,6]$. There is however a third kind mostly popular in Asia commonly referred to as white tea; it shares similar processing to green tea but differs only in the stage of maturity in which the tea leaves are picked/harvested. Commercially grown teas are hybrids of two distinct types, the Assam type (var. assamica) and the China type (var. sinensis) [6]. GT from the genus 
of Camellia are rich sources of polyphenols particularly flavonoids of the subclass catechins and its derivatives called tea catechins or flavan-3-ols including catechin, epicatechin, epigallocatechin, epicatechin gallate, epigallocatechin gallate, and gallocatechin gallate. The fermentation process that produces BT results in the oxidation of the catechins by polyphenol oxidase into polymeric compounds, thearubigins, and theaflavins $[5,7,8]$. Several medicinal properties such as anticancer [8], hypocholesterolemic effects [9], antibacterial $[10,11]$, and antioxidant effects [12] that have been associated with tea are attributed to its rich polyphenol content. Several lines of study have shown an inverse relationship between tea consumption and hyperglycemia $[13,14]$, incidence of type- 2 diabetes [15]. As a result, in this study the hypothesis that the molecular mechanisms by which teas from Camellia sinensis exert the observed antidiabetic effects that was through inhibition of carbohydrate metabolizing enzymes implicated in diabetes pathology was tested.

\section{Materials and Methods}

2.1. Sample Collection. Four different commercial samples of bagged tea leaves of three brands were purchased from supermarkets in Akure metropolis. These included green tea (GT), two black teas (BT1 and BT2), and a formulated herbal preparation for diabetes (ADT) composed of white tea (63.4\%), Radix puerariae (8\%), Radix ophiopogonis (6.2\%), hawthorn berry (10\%), Chinese yam (6.2\%), and fragrant Solomon seal rhizome (6.2\%).

2.2. Sample Preparation. $1 \mathrm{~g}$ of each sample was extracted in $100 \mathrm{~mL}$ of hot water for about five minutes after which they were filtered. The filtrates were kept in $-20^{\circ} \mathrm{C}$ until usage for subsequent analysis.

2.3. Determination of Vitamin C. Vitamin C content of the samples was determined using the method of Benderitter et al. [16]. Briefly, $75 \mu \mathrm{L}$ DNPH (2 g dinitrophenyl hydrazine, $230 \mathrm{mg}$ thiourea, and $\mathrm{CuSO}_{4} \cdot 5 \mathrm{H}_{2} \mathrm{O}$ in $100 \mathrm{~mL}$ of $\mathrm{H}_{2} \mathrm{SO}_{4}$ ) was added to $500 \mu \mathrm{L}$ reaction mixture $(300 \mu \mathrm{L}$ of appropriate dilution of the extracts with $100 \mu \mathrm{L}$ of $13.3 \%$ trichloroacetic acid (TCA)) and water. The reaction mixture was subsequently incubated for 3 hours at $37^{\circ} \mathrm{C}$, then $0.5 \mathrm{~mL}$ of $65 \% \mathrm{H}_{2} \mathrm{SO}_{4}(\mathrm{v} / \mathrm{v})$ was added to the medium, and the absorbance was measured at $520 \mathrm{~nm}$ using spectrophotometer. The vitamin $\mathrm{C}$ content of the extracts was subsequently calculated using ascorbic acid as standard.

2.4. Determination of Total Phenol Content. The total phenol content of the samples was determined according to the method of Singleton et al. [17]. Briefly, appropriate dilutions of tea extracts were oxidized with $2.5 \mathrm{~mL} \mathrm{10 \%} \mathrm{Folin-}$ Ciocalteau's reagent (v/v) and neutralized by $2.0 \mathrm{~mL}$ of $7.5 \%$ sodium carbonate. The reaction mixture was incubated for 40 minutes at $45^{\circ} \mathrm{C}$ and the absorbance was measured at $765 \mathrm{~nm}$ using a spectrophotometer. The total phenol contents were subsequently calculated and represented as gallic acid equivalents (GAE).
2.5. Total Antioxidant Capacity. The ABTS scavenging ability of the extracts was determined according to the method described by $\mathrm{Re}$ et al. [18]. ABTS radicals were generated by reacting aqueous solution of ABTS (7 mM) with $\mathrm{K}_{2} \mathrm{~S}_{2} \mathrm{O}_{8}$ (final concentration of $2.45 \mathrm{mM}$ ) in the dark for 16 hours and adjusting the absorbance at $734 \mathrm{~nm}$ to $0.700 .200 \mu \mathrm{L}$ of the extract was added to $2.0 \mathrm{~mL}$ ABTS solution and the absorbance was measured at $734 \mathrm{~nm}$ after 15 minutes. The trolox equivalent antioxidant capacity was subsequently calculated.

2.6. Determination of Reducing Property. The Reducing property of the extract was determined by assessing the ability of the extracts to reduce $\mathrm{FeCl}_{3}$ solution as described by [19]. Briefly, appropriate dilutions of the extracts $(2.5 \mathrm{~mL})$ were mixed with $2.5 \mathrm{~mL} 200 \mathrm{mM}$ sodium phosphate buffer ( $\mathrm{pH}$ 6.6) and $2.5 \mathrm{~mL}$ of $1 \%$ potassium ferricyanide. The mixture was incubated at $50^{\circ} \mathrm{C}$ for 20 minutes. Thereafter, $2.5 \mathrm{~mL} 10 \%$ trichloroacetic acid was added and subsequently centrifuged at $650 \mathrm{rpm}$ for 10 minutes. $5 \mathrm{~mL}$ of the resulting supernatant was mixed with equal volume of water and $1 \mathrm{~mL}$ of $0.1 \%$ ferric chloride. The absorbance was taken at $700 \mathrm{~nm}$ against a reagent blank.

\subsection{Lipid Peroxidation Assay}

2.7.1. Tissue Preparation. The pancreas of the rat was quickly removed, placed on ice, and weighed. This tissue was subsequently homogenized in cold saline $(150 \mathrm{mM})(1: 10 \mathrm{w} / \mathrm{v})$ using mortar and pestle. The homogenate was centrifuged for 10 minutes at about $2000 \mathrm{rpm}$ to yield a pellet that was discarded and a low-speed supernatant (S1) was kept for lipid peroxidation assay [20].

2.7.2. Lipid Peroxidation and Thiobarbituric Acid Reactions. The lipid peroxidation assay was carried out using the method of Pulido et al. [19] as modified by Puntel et al. [21] with two prooxidants $\left(\mathrm{Fe}^{2+}\right.$ and sodium nitroprusside). Briefly, $1 \mathrm{~mL}$ of the $\mathrm{S} 1$ fraction was mixed with a reaction mixture containing $300 \mu \mathrm{L}$ and $10 \mathrm{mM}$ Tris- $\mathrm{HCl}$ ( $\mathrm{pH} 7.4$ ), and the volume was made up to $3 \mathrm{~mL}$ with distilled water, then $300 \mu \mathrm{L}$ of the extract was added before incubation at $37^{\circ} \mathrm{C}$ for 1 hour. The colour reaction was developed by adding $3 \mathrm{~mL}$ of $8.1 \%$ SDS (sodium duodecyl sulphate) to the reaction mixture containing S1; this was subsequently followed by the addition of $5 \mathrm{~mL}$ acetic acid solution $(\mathrm{pH} 3.4)$ and $5 \mathrm{~mL} 0.6 \%$ TBA (thiobarbituric acid). This mixture was then incubated at $100^{\circ} \mathrm{C}$ for 1 hour. Thiobarbituric acid reactive species (TBARS) produced were measured at $534 \mathrm{~nm}$ and the absorbance was compared with that of standard curve using malondialdehyde (MDA).

\subsection{Enzyme Inhibition Assays}

2.8.1. $\alpha$-Amylase Inhibition Assay. Appropriate dilution of the tea extracts $(500 \mu \mathrm{L})$ and $500 \mu \mathrm{L}$ of $0.02 \mathrm{M}$ sodium phosphate buffer ( $\mathrm{pH} 6.9$ with $0.006 \mathrm{M} \mathrm{NaCl}$ ) containing Hog pancreatic $\alpha$-amylase (EC 3.2.1.1) $(0.5 \mathrm{mg} / \mathrm{mL})$ were 


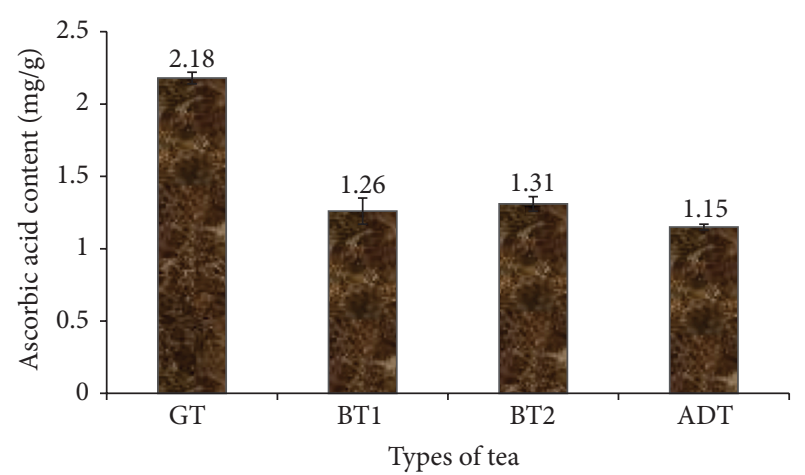

FIGURE 1: Ascorbic acid content of some commercially available tea. GT: Green tea; BT: Black tea; ADT: antidiabetes tea.

incubated at $25^{\circ} \mathrm{C}$ for 10 minutes. Thereafter, $50 \mu \mathrm{L}$ of $1 \%$ starch solution in $0.02 \mathrm{M}$ sodium phosphate buffer ( $\mathrm{pH} 6.9$ with $0.006 \mathrm{M} \mathrm{NaCl}$ ) was added to each tube. The reaction mixture was incubated at $25^{\circ} \mathrm{C}$ for 10 minutes and stopped with $1 \mathrm{~mL}$ of dinitrosalicylic acid (DNSA) colour reagent. Thereafter, the mixture was incubated in a boiling water bath for 5 minutes and cooled to room temperature. The reaction mixture was then diluted by adding $10 \mathrm{~mL}$ of distilled water, and absorbance measured at $540 \mathrm{~nm}$.

2.8.2. $\alpha$-Glucosidase Inhibition Assay. Appropriate dilution of the extract $(50 \mu \mathrm{L})$ and $100 \mu \mathrm{L}$ of $\alpha$-glucosidase solution $(1 \mathrm{U} / \mathrm{mL})$ in $0.1 \mathrm{M}$ phosphate buffer $(\mathrm{pH} 6.9)$ was incubated at $37^{\circ} \mathrm{C}$ for 10 minutes. Then $40 \mu \mathrm{l}$ of $5 \mathrm{mM}$ p-nitrophenyl$\alpha$-D-glucosidase solution in $0.1 \mathrm{M}$ phosphate buffer $(\mathrm{pH}$ 6.9) was added. The mixture was incubated at $37^{\circ} \mathrm{C}$ for 10 minutes before reading the absorbance at $405 \mathrm{~nm}$ in the spectrophotometer. The $\alpha$-glucosidase inhibitory activity was expressed as percentage inhibition.

2.9. Data Analysis. The results of triplicate studies were pooled and expressed as mean \pm standard error of mean (SEM). A one-way analysis of variance was carried out. Significance was accepted at $P>0.05 . \mathrm{EC}_{50}$ was further determined by nonlinear regression analysis.

\section{Results}

In this study, the ascorbic acid contents of the tea brands as presented in Figure 1 revealed that green tea GT $(2.18 \pm 0.04 \mathrm{mg} / \mathrm{g})$ was significantly $(P<0.05)$ higher in ascorbic acid than black teas (BT1: $1.26 \pm 0.09 \mathrm{mg} / \mathrm{g}$; BT2: $1.31 \pm 0.05 \mathrm{mg} / \mathrm{g}$ ) and antidiabetic tea (ADT: $1.15 \pm 0.02 \mathrm{mg} / \mathrm{g}$ ). Determined total phenol content (TPC) of infusions from some teas (Figure 2) shows that green tea $(9.51 \pm 1.55 \mathrm{mg} / \mathrm{g})$ had a significantly $(P<0.05)$ higher phenolic content than fermented black teas (BT1: $6.05 \pm 1.10 \mathrm{mg} / \mathrm{g}$; BT2: $5.42 \pm 0.98 \mathrm{mg} / \mathrm{g})$ and the formulated antidiabetic tea (ADT: $5.01 \pm 1.12 \mathrm{mg} / \mathrm{g}$ ). However, there was no significant difference $(P>0.05)$ between the two brands of black teas (BT1 and BT2) and ADT.

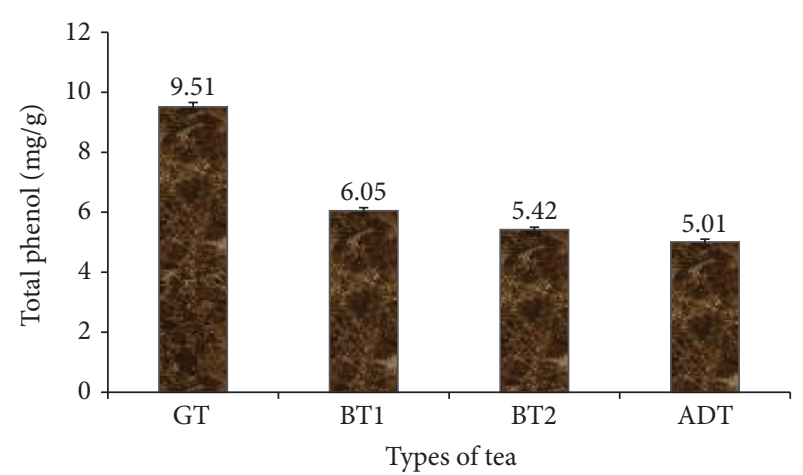

Figure 2: Total phenol content of some commercially available tea. GT: Green tea; BT: Black tea; ADT: antidiabetes tea.

TABLE 1: 2,2-Azizobis (3-ethylbenzothiazoline 6-sulfonate) "ABTS" scavenging ability and ferric reducing antioxidant property of some commercial teas.

\begin{tabular}{lcc}
\hline Sample & ABTS $(\mathrm{mmol} \cdot \mathrm{TEAC} / 100 \mathrm{~g})$ & FRAP $(\mathrm{AAE} \mathrm{mg} / \mathrm{g})$ \\
\hline GT & $5.54 \pm 1.21^{\mathrm{a}}$ & $15.98 \pm 2.31^{\mathrm{a}}$ \\
BT1 & $1.80 \pm 1.54^{\mathrm{b}}$ & $12.01 \pm 1.87^{\mathrm{b}}$ \\
BT2 & $2.80 \pm 0.96^{\mathrm{b}}$ & $9.26 \pm 1.32^{\mathrm{d}}$ \\
ADT & $4.70 \pm 1.08^{\mathrm{a}}$ & $10.12 \pm 1.91^{\mathrm{c}}$ \\
\hline
\end{tabular}

GT: green tea; BT: black tea; ADT: antidiabetes tea. Values represent means of triplicate of duplicate experiments. Values with the same letter along the same column are not significantly different $(P>0.05)$.

The ABTS* scavenging ability of the tea represented as trolox equivalent antioxidant capacity (TEAC) are presented in Table 1 . The results revealed that GT $(5.54 \pm 1.21)$ and ADT $(4.70 \pm 1.08)$ were significantly $(P<0.05)$ higher than the black teas (BT1: $1.80 \pm 1.54$; BT2: $2.80 \pm 0.96$ ). The fermented black teas also did not show any significant $(P>0.05)$ difference in their total antioxidant capacity when compared with each other. Furthermore, the ferric reducing antioxidant property was determined and is presented in Table 1 as ascorbic acid equivalents.

We investigated further the antioxidant effect of the teas by interacting the tea infusions with isolated rat pancreas in the presence of $\mathrm{Fe}^{2+}$ and sodium nitroprusside (SNP) as prooxidants (Figures 3(a) and 3(b)). There was significant $(P>0.05)$ increase in the malondialdehyde (MDA) content of the pancreas after incubation with $25 \mu \mathrm{M} \mathrm{Fe}^{2+}(200.0 \pm$ $6.1 \%)$ and $5 \mathrm{mM} \mathrm{SNP}(150 \pm 3.4 \%)$. However, the tea infusions caused a dose $(25-100 \mathrm{mg} / \mathrm{mL})$ dependent decrease in the MDA content of the pancreas in the presence of $\mathrm{Fe}^{2+}$ and SNP. The $\mathrm{EC}_{50}$ results show that GT $(2.77 \pm 0.86)$ was most effective against $\mathrm{Fe}^{2+}$ induced lipid peroxidation when compared with the other teas (BT1: $3.37 \pm 1.09$; BT2: $3.42 \pm$ 0.95 ; ADT: $3.51 \pm 1.34)$. Meanwhile, there was no significant $(P<0.05)$ difference in the ability of GT $(3.41 \pm 1.02)$ and BT1 $(3.10 \pm 1.27)$ to inhibit SNP induced lipid peroxidation. However, BT2 (7.62 \pm 1.57$)$ showed the least inhibitory effect.

In a bid to further assess the antidiabetic potentials of the teas, the inhibitory activity of the tea infusions on $\alpha$ amylase was determined (Figure 4). The teas showed a dose 


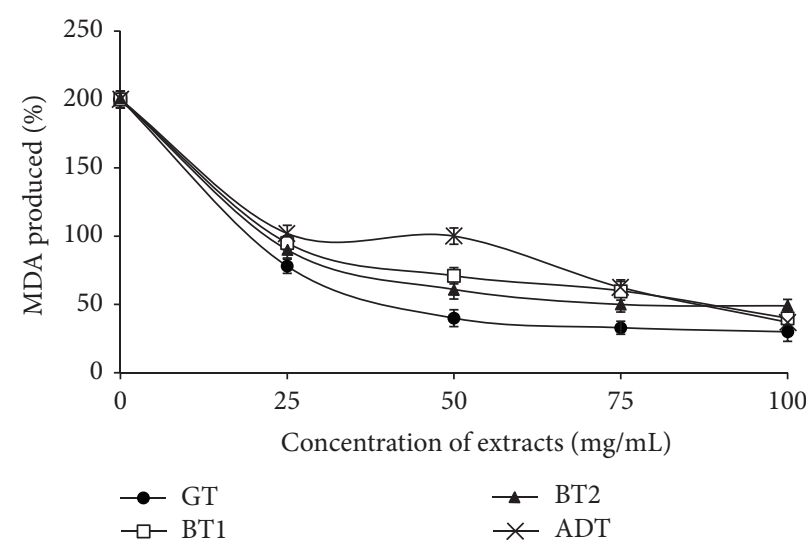

(a)

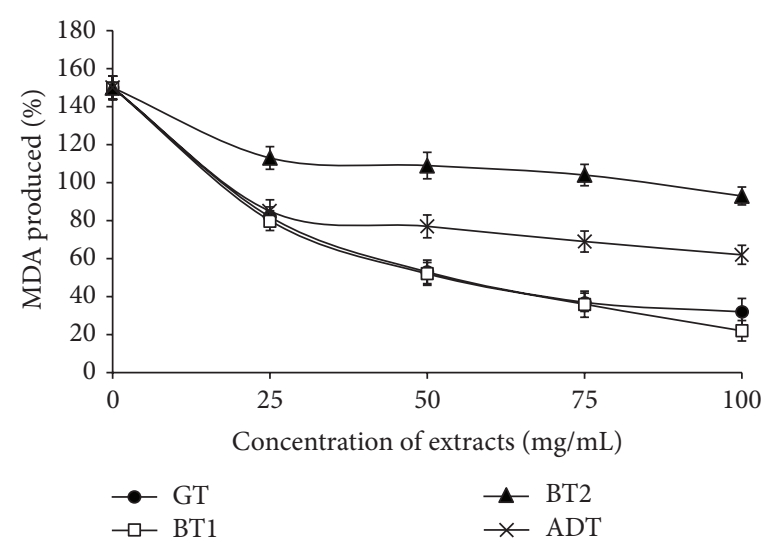

(b)

FIGURE 3: (a) Inhibition of $\mathrm{Fe}^{2+}$ induced lipid peroxidation in rat pancreas by aqueous extracts from some commercially available teas. GT: Green tea; BT: Black tea; ADT: antidiabetes tea. (b) Inhibition of sodium nitroprusside (SNP) induced lipid peroxidation in rat pancreas by tea infusion from some commercially available teas. GT: Green tea; BT: Black tea; ADT: antidiabetes tea.

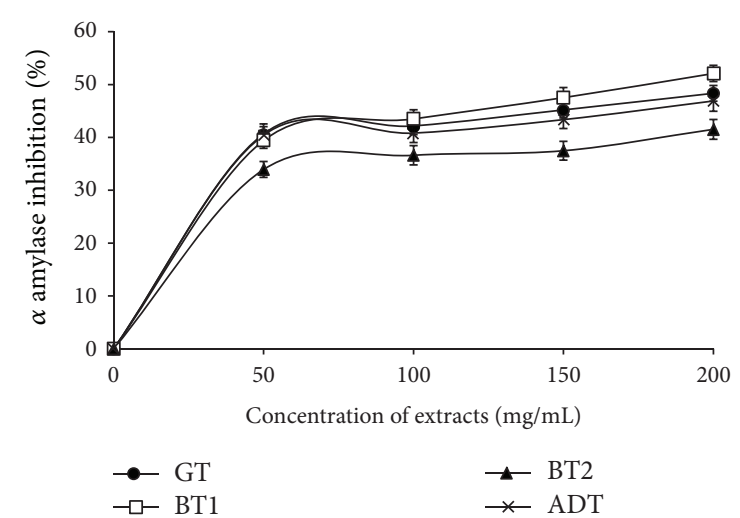

FIGURE 4: Inhibition of $\alpha$-amylase by aqueous extracts of aqueous extracts from some commercially available teas. GT: Green tea; BT: Black tea; ADT: antidiabetes tea.

dependent inhibition of $\alpha$-amylase $(50-200 \mathrm{mg} / \mathrm{mL})$. The $\mathrm{EC}_{50}$ results revealed that there was no significant difference in the ability of the tea infusions (BT1: $4.03 \pm 1.21$; GT: $4.36 \pm 0.84$; ADT: $4.62 \pm 0.92)$ to inhibit $\alpha$-amylase except in the case of BT2 (5.94 \pm 1.42$)$, where there was a significantly lower inhibitory activity. Similarly, the tea infusions inhibited $\alpha$-glucosidase in a dose dependent manner $(50-200 \mathrm{mg} / \mathrm{mL})$ and the $\mathrm{EC}_{50}$ results also showed that there was no significant difference in the inhibitory activity of the teas (Figure 5). Figure 6 showed the correlation between the total phenol content and ferric reducing antioxidant properties of the commercially available teas. The $R^{2}$ value was 0.8506 , which showed a strong correlation.

\section{Discussion}

Evidences have accumulated in the last few years indicating that tea consumption is inversely correlated with the incidence of diabetes. We therefore sought to assess the ability of

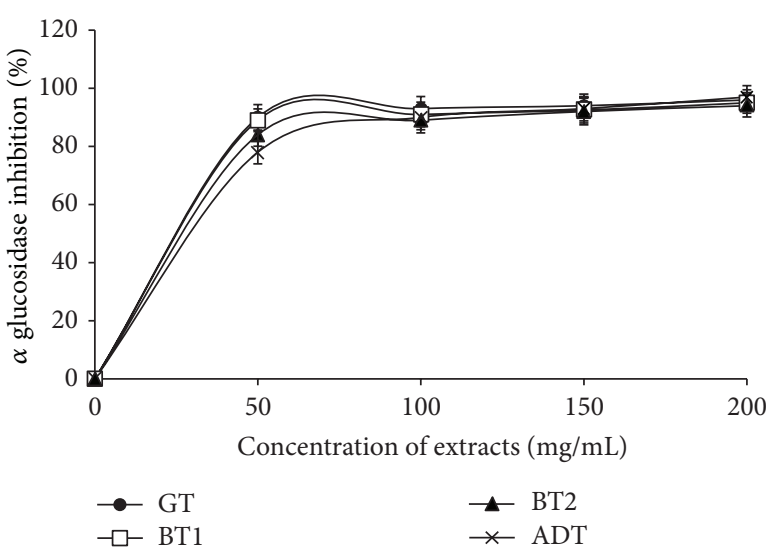

FIGURE 5: Inhibition of $\alpha$-glucosidase by aqueous extracts from some commercially available teas. GT: Green tea; BT: Black tea; ADT: antidiabetes tea.

tea infusions to inhibit carbohydrate metabolizing enzymes and their antioxidant effects. The ascorbic acid content of the teas is lower than that reported for Salvia officinalis [22] but higher than that of Capsicum pubescens [23]. The difference in the ascorbic acid content of GT and BTs could have resulted from the fermentation processing of black teas. In a recent study by Moraes et al. [24] a decline in the ascorbic acid content of vegetables was also observed with different processing techniques. Furthermore, taking into consideration that the major constituent of the ADT used in this study is white tea; the significant difference in ascorbic acid between both could be a result of the maturity of the leaves. This is in agreement with studies by Lim and Quah [25], where increase in ascorbic acid was observed with maturity. All known physiological and biochemical actions of ascorbic acid is due to its actions as an electron donor whereby it loses two electrons sequentially resulting in the formation of relatively 


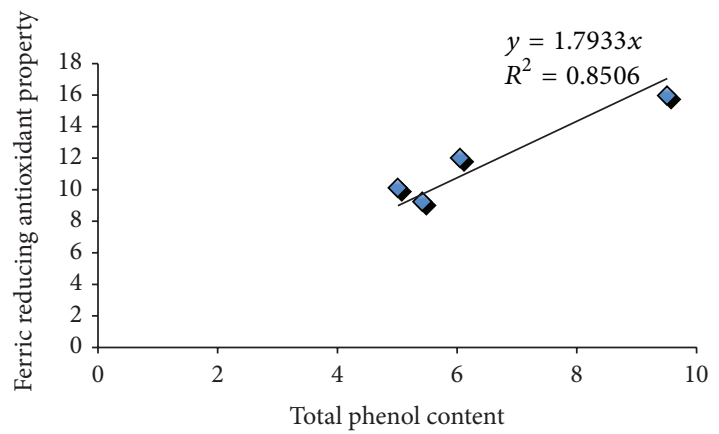

FIGURE 6: Relationship between the total phenol content and ferric reducing antioxidant properties of some commonly commercially available teas.

stable ascorbyl radical and dehydroascorbic acid, respectively. This known chemical property of vitamin $\mathrm{C}$ forms the basis for it free radical quenching ability [26].

The significant difference in total phenol contents between GT and BT agrees with earlier studies [27], which could be attributed to the fermentation process which black teas are subjected to. Kim et al. [5] reported a decrease of up to $37.2 \%$ in total soluble free phenolics of Camellia sinensis with increasing period in fermentation. TPC of the teas observed in this study is lower than previously reported values for green tea and black tea $[6,23]$ except for green tea, which was comparable to some other commercially available black teas in Argentina as reported by Anesini et al. [6]. This difference could be a result of the mode of extraction utilized. However, the TPC of the teas were also comparable to the total phenol content of Salvia officinalis [22], some citrus juices [28] and Capsicum spp. [29].

Reducing power is a novel antioxidation defense mechanism; the two mechanisms available to affect this property are by electron transfer and hydrogen atom transfer [30]. This is because the ferric-to-ferrous ion reduction occurs rapidly with all reductants with half reaction reduction potentials above that of $\mathrm{Fe}^{3+} / \mathrm{Fe}^{2+}$, the values in the Ferric reducing antioxidant property (FRAP) assay will express the corresponding concentration of electron-donating antioxidants [31]. The order of reducing power of the tea infusions is as follows GT $>$ BT1 > ADT > BT2 $(P<0.05)$. These findings are similar to other studies, where GT had consistently shown a higher antioxidant activity than black teas [32]. These can be attributed to the significantly higher total phenol and ascorbic acid contents of green tea. There was strong correlation between the the total phenol content and ferric reducing antioxidant properties of the commercially available teas as shown by the $R^{2}$ value. This is similar to previous studies, where strong correlation between antioxidants properties of plant foods and their phenolic content have been established [32].

Lipid peroxidation has been implicated in various diseases resulting in free radical mediated release of MDA particularly from membrane lipids. As such, various kinds of antioxidants with different functions inhibit lipid peroxidation and the deleterious effects caused by the lipid peroxidation products [33]. The molecular mechanisms by which the $\mathrm{Fe}^{2+}$ could have resulted in the MDA increase could have been through its ability to participate in one-electron transfer reactions, whereby $\mathrm{OH}$ radicals are generated from $\mathrm{H}_{2} \mathrm{O}_{2}$ via the Fenton reaction. Iron has also been known to favor the propagation of lipid oxidation by decomposition of lipid peroxides resulting in peroxyl and alkoxyl radicals [22]. On the other hand, SNP toxicity is mediated through its release of cyanide and/or NO [34]. Although NO is considered to be cytoprotective at low concentrations, higher concentrations are considered toxic [35]. Its cytotoxicity is based on its ability to form peroxyl nitrite radicals in conjunction with other reactive oxygen species [36]. Furthermore, decomposition of SNP results in the release of iron that could further propagate the chain reaction of lipid peroxidation via the Fenton reaction [37].

The observed inhibitory effect of the teas on $\mathrm{Fe}^{2+}$ and SNP induced lipid peroxidation could have been a result of the teas being able to neutralize the $\mathrm{OH}$ and $\mathrm{NO}$ radicals produced by the prooxidants. Also there is the possibility that the tea extracts were able to chelate $\mathrm{Fe}^{2+}$ thereby attenuating its exacerbating effect as observed in the decrease in MDA content when incubated with the tea extracts. Plant polyphenols are known to exert antioxidant activity through the reduction/chelation of transition metals or scavenging of free radicals [38]. The higher inhibitory property of GT is worthnoting and could be attributed to the higher bioactivity of the tea catechins. It is noteworthy that the observed antioxidant activities of the teas at the concentrations used is similar to previous study [39].

Hyperglycemia is characterized by abnormal increases in postprandial blood glucose and is complicit in the etiology of type-2 diabetes [40, 41]. Increased activities of pancreatic $\alpha$-amylase and intestinal $\alpha$-glucosidase enzymes involved in starch hydrolysis have been reported in experimental diabetic animal models [42]. This justifies the pharmacological use of $\alpha$-amylase and $\alpha$-glucosidase inhibitors in treatment and management of type- 2 diabetes. The use of phenolics particularly from dietary sources has been advocated as $\alpha$-amylase and $\alpha$-glucosidase inhibitors [43].

Furthermore, in a meta-analysis, [15] reported estimates indicating that individuals who drank more than 3 to 4 cups of tea per day had an approximate one-fifth lower risk of DM than those consuming no tea. Interestingly, several lines of study have revealed that GT can lower postprandial hyperglycemia and its associated complication [44]. The results from this study underscore the possible mechanism by which teas could have exerted their hypoglycemic effect and antidiabetic potentials.

\section{Conclusion}

It is possible to conclude from this study that green tea has higher antioxidant activity that could be attributed to its higher total phenol and ascorbic acid contents. However it was no more effective than the other teas in its antidiabetic potentials. 


\section{Conflict of Interests}

The authors declare that there is no conflict of interests regarding the publication of this paper.

\section{References}

[1] International Diabetes Federation, The Global Burden, 2011, www.idf.org/diabetesatla.

[2] K. Sama, K. Murugesan, and R. Sivaraj, "In vitro alpha amylase and alpha glucosidase inhibition activity of crude ethanol extract of Cissus arnottiana," Asian Journal of Plant Science and Research, vol. 2, no. 4, pp. 550-553, 2012.

[3] R. Tundis, F. Menichini, M. R. Loizzo, M. Bonesi, U. Solimene, and F. Menichini, "Studies on the potential antioxidant properties of Senecio stabianus Lacaita (Asteraceae) and its inhibitory activity against carbohydrate- hydrolysing enzymes," Natural Product Research, vol. 26, no. 5, pp. 393-404, 2012.

[4] Y.-I. I. Kwon, D. A. Vattem, and K. Shetty, "Evaluation of clonal herbs of Lamiaceae species for management of diabetes and hypertension," Asia Pacific Journal of Clinical Nutrition, vol. 15, no. 1, pp. 107-118, 2006.

[5] Y. Kim, K. L. Goodner, J.-D. Park, J. Choi, and S. T. Talcott, "Changes in antioxidant phytochemicals and volatile composition of Camellia sinensis by oxidation during tea fermentation," Food Chemistry, vol. 129, no. 4, pp. 1331-1342, 2011.

[6] C. Anesini, G. E. Ferraro, and R. Filip, "Total polyphenol content and antioxidant capacity of commercially available tea (Camellia sinensis) in Argentina," Journal of Agricultural and Food Chemistry, vol. 56, no. 19, pp. 9225-9229, 2008.

[7] P. D. B. Ribaldo, D. S. Souza, S. K. Biswas, K. Block, J. M. L. De Faria, and J. B. L. De Faria, "Green tea (Camellia sinensis) attenuates nephropathy by downregulating Nox4 NADPH oxidase in diabetic spontaneously hypertensive rats," Journal of Nutrition, vol. 139, no. 1, pp. 96-100, 2009.

[8] K. A. Grove and J. D. Lambert, "Laboratory, epidemiological, and human intervention studies show that tea (Camellia sinensis) may be useful in the prevention of obesity," Journal of Nutrition, vol. 140, no. 3, pp. 446-453, 2010.

[9] M.-H. Yang, C.-H. Wang, and H.-L. Chen, "Green, oolong and black tea extracts modulate lipid metabolism in hyperlipidemia rats fed high-sucrose diet," The Journal of Nutritional Biochemistry, vol. 12, no. 1, pp. 14-20, 2001.

[10] S. Archana and J. Abraham, "Comparative analysis of antimicrobial activity of leaf extracts from fresh green tea, commercial green tea and black tea on pathogens," Journal of Applied Pharmaceutical Science, vol. 1, no. 8, pp. 149-152, 2011.

[11] T. I. Mbata, L. U. Debiao, and A. Saikia, "Antibacterial activity of the crude extract of Chinese green tea (Camellia sinensis) on Listeria monocytogenes," African Journal of Biotechnology, vol. 7, no. 10, pp. 1571-1573, 2008.

[12] G. Oboh and J. B. T. Rocha, "Water extractable phytochemicals from Capsicum pubescens (tree pepper) inhibit lipid peroxidation induced by different pro-oxidant agents in brain: in vitro," European Food Research and Technology, vol. 226, no. 4, pp. 707713, 2008.

[13] K. Hosoda, M.-F. Wang, M.-L. Liao et al., "Antihyperglycemic effect of oolong tea in type 2 diabetes," Diabetes Care, vol. 26, no. 6, pp. 1714-1718, 2003.
[14] The InterAct Consortium, "Tea consumption and incidence of type 2 diabetes in Europe: The EPIC-InterAct Case-Cohort Study," PLOS ONE, vol. 7, no. 5, 2012.

[15] R. Huxley, C. M. Y. Lee, F. Barzi et al., "Coffee, decaffeinated coffee, and tea consumption in relation to incident type 2 diabetes mellitus: a systematic review with meta-analysis," Archives of Internal Medicine, vol. 169, no. 22, pp. 2053-2063, 2009.

[16] M. Benderitter, V. Maupoil, C. Vergely, F. Dalloz, F. Briot, and L. Rochette, "Studies by electron paramagnetic resonance of the importance of iron in the hydroxyl scavenging properties of ascorbic acid in plasma: effects of iron chelators," Fundamental and Clinical Pharmacology, vol. 12, no. 5, pp. 510-516, 1998.

[17] V. L. Singleton, R. Orthofer, and R. M. Lamuela-Raventós, "Analysis of total phenols and other oxidation substrates and antioxidants by means of folin-ciocalteu reagent," Methods in Enzymology, vol. 299, pp. 152-178, 1998.

[18] R. Re, N. Pellegrini, A. Proteggente, A. Pannala, M. Yang, and C. Rice-Evans, "Antioxidant activity applying an improved ABTS radical cation decolorization assay," Free Radical Biology and Medicine, vol. 26, no. 9-10, pp. 1231-1237, 1999.

[19] R. Pulido, L. Bravo, and F. Saura-Calixto, "Antioxidant activity of dietary polyphenols as determined by a modified ferric reducing/antioxidant power assay," Journal of Agricultural and Food Chemistry, vol. 48, no. 8, pp. 3396-3402, 2000.

[20] H. Ohkawa, N. Ohishi, and K. Yagi, "Assay for lipid peroxides in animal tissues by thiobarbituric acid reaction," Analytical Biochemistry, vol. 95, no. 2, pp. 351-358, 1979.

[21] R. L. Puntel, C. W. Nogueira, and J. B. T. Rocha, "Krebs cycle intermediates modulate thiobarbituric acid reactive species (TBARS) production in rat brain in vitro," Neurochemical Research, vol. 30, no. 2, pp. 225-235, 2005.

[22] G. Oboh and T. Henle, "Antioxidant and inhibitory effects of aqueous extracts of Salvia officinalis leaves on pro-oxidantinduced lipid peroxidation in brain and liver in vitro," Journal of Medicinal Food, vol. 12, no. 1, pp. 77-84, 2009.

[23] G. Oboh and J. B. T. Rocha, "Antioxidant and neuroprotective properties of sour tea (Hibiscus sabdariffa, calyx) and green tea (Camellia sinensis) on some pro-oxidant-induced lipid peroxidation in brain in vitro," Food Biophysics, vol. 3, no. 4, pp. 382-389, 2008.

[24] F. A. Moraes, A. M. Cota, F. M. Campos, and H. M. PinheiroSant'Ana, "Vitamin C loss in vegetables during storage, preparation and distribution in restaurants," Ciencia e Saude Coletiva, vol. 15, no. 1, pp. 51-62, 2010.

[25] Y. Y. Lim and E. P. L. Quah, "Antioxidant properties of different cultivars of Portulaca oleracea," Food Chemistry, vol. 103, no. 3, pp. 734-740, 2007.

[26] S. J. Padayatty, A. Katz, Y. Wang et al., "Vitamin C as an antioxidant: evaluation of its role in disease prevention," Journal of the American College of Nutrition, vol. 22, no. 1, pp. 18-35, 2003.

[27] A. Büyükbalci and S. N. El, "Determination of in vitro antidiabetic effects, antioxidant activities and phenol contents of some herbal teas," Plant Foods for Human Nutrition, vol. 63, no. 1, pp. 27-33, 2008.

[28] A. O. Ademosun and G. Oboh, "Inhibition of acetylcholinesterase activity and $\mathrm{Fe}^{2+}$-induced lipid peroxidation in rat brain in vitro by some citrus fruit juices," Journal of Medicinal Food, vol. 15, no. 5, pp. 428-434, 2012. 
[29] G. Oboh and O. O. Ogunruku, "Cyclophosphamide-induced oxidative stress in brain: protective effect of hot short pepper (Capsicum frutescens L. var. abbreviatum)," Experimental and Toxicologic Pathology, vol. 62, no. 3, pp. 227-233, 2010.

[30] H. Göçer and I. Gülçin, "Caffeic acid phenethyl ester (CAPE): correlation of structure and antioxidant properties," International Journal of Food Sciences and Nutrition, vol. 62, no. 8, pp. 821-825, 2011.

[31] B. C. Adedayo, A. O. Ademiluyi, G. Oboh, and A. A. Akindahunsi, "Interaction of aqueous extracts of two varieties of Yam tubers (Dioscorea spp) on some key enzymes linked to type 2 diabetes in vitro," International Journal of Food Science and Technology, vol. 47, no. 4, pp. 703-709, 2012.

[32] P. Carloni, L. Tiano, L. Padella et al., "Antioxidant activity of white, green and black tea obtained from the same tea cultivar," Food Research International, vol. 53, no. 2, pp. 900-908, 2013.

[33] E. Niki, Y. Yoshida, Y. Saito, and N. Noguchi, "Lipid peroxidation: mechanisms, inhibition, and biological effects," Biochemical and Biophysical Research Communications, vol. 338, no. 1, pp. 668-676, 2005.

[34] Q. A. Nazari, K. Mizuno, T. Kume, Y. Takada-Takatori, Y. Izumi, and A. Akaike, "In vivo brain oxidative stress model induced by microinjection of sodium nitroprusside in mice," Journal of Pharmacological Sciences, vol. 120, no. 2, pp. 105-111, 2012.

[35] H.-C. Um, J.-H. Jang, D.-H. Kim, C. Lee, and Y.-J. Surh, "Nitric oxide activates Nrf2 through S-nitrosylation of Keap1 in PC12 cells," Nitric Oxide, vol. 25, no. 2, pp. 161-168, 2011.

[36] P. Calcerrada, G. Peluffo, and R. Radi, "Nitric oxide-derived oxidants with a focus on peroxynitrite: molecular targets, cellular responses and therapeutic implications," Current Pharmaceutical Design, vol. 17, no. 35, pp. 3905-3932, 2011.

[37] C. Wagner, R. Fachinetto, C. L. D. Corte et al., "Quercitrin, a glycoside form of quercetin, prevents lipid peroxidation in vitro," Brain Research, vol. 1107, no. 1, pp. 192-198, 2006.

[38] G. Sasipriya and P. Siddhuraju, "Effect of different processing methods on antioxidantactivity of underutilized legumes, Entada scandens seed kernel and Canavalia gladiata seeds," Food and Chemical Toxicology, vol. 50, no. 8, pp. 2864-2872, 2012.

[39] G. Oboh and J. B. T. Rocha, "Antioxidant and neuroprotective properties of sour tea (Hibiscus sabdariffa, calyx) and green tea (Camellia sinensis) on some pro-oxidant-induced lipid peroxidation in brain in vitro," Food Biophysics, vol. 3, no. 4, pp. 382-389, 2008.

[40] T. Nishikawa, D. Edelstein, X. L. Du et al., "Normalizing mitochondrial superoxide production blocks three pathways of hyperglycaemic damage," Nature, vol. 404, no. 6779, pp. 787790, 2000.

[41] O. V. Sakharova, R. R. Lleva, J. D. Dziura et al., "Effects on postprandial glucose and AGE precursors from two initial insulin strategies in patients with type 2 diabetes uncontrolled by oral agents," Journal of Diabetes and its Complications, vol. 26, no. 4, pp. 333-338, 2012.

[42] M. A. Tormo, I. Gil-Exojo, A. Romero de Tejada, and J. E. Campillo, "White bean amylase inhibitor administered orally reduces glycaemia in type 2 diabetic rats," The British Journal of Nutrition, vol. 96, no. 3, pp. 539-544, 2006.

[43] M. Yilmazer-Musa, A. M. Griffith, A. J. . Michels, E. Schneider, and B. Frei, "Grape seed and tea extracts and catechin 3-gallates are potent inhibitors of $\alpha$-Amylase and $\alpha$-Glucosidase activity,"
Journal of Agriculture and Food Chemistry, vol. 60, no. 36, pp. 8924-8929, 2012.

[44] F. Haidari, M. M. Shahi, M. Zarei, H. Rafiei, and K. Omidian, "Effect of green tea extract on body weight, serum glucose and lipid profile in streptozotocin-induced diabetic rats: a dose response study," Saudi Medical Journal, vol. 33, no. 2, pp. 128$133,2012$. 


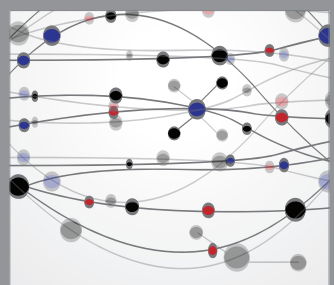

The Scientific World Journal
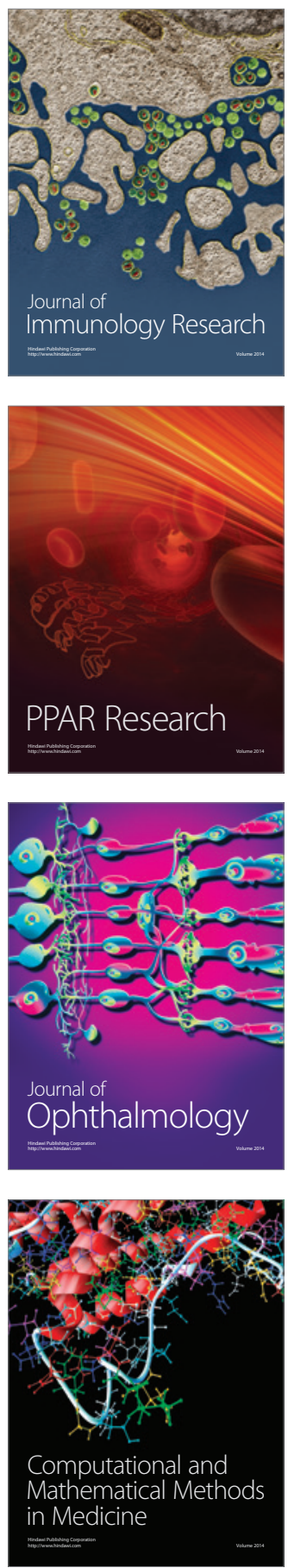

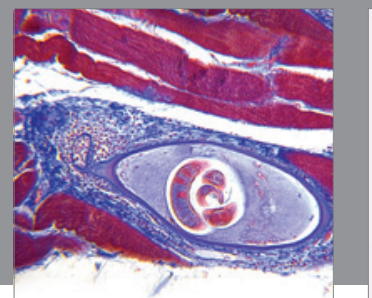

Gastroenterology

Research and Practice
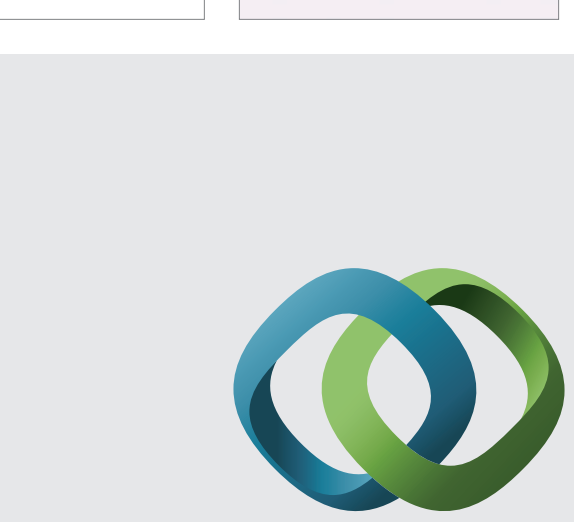

\section{Hindawi}

Submit your manuscripts at

http://www.hindawi.com
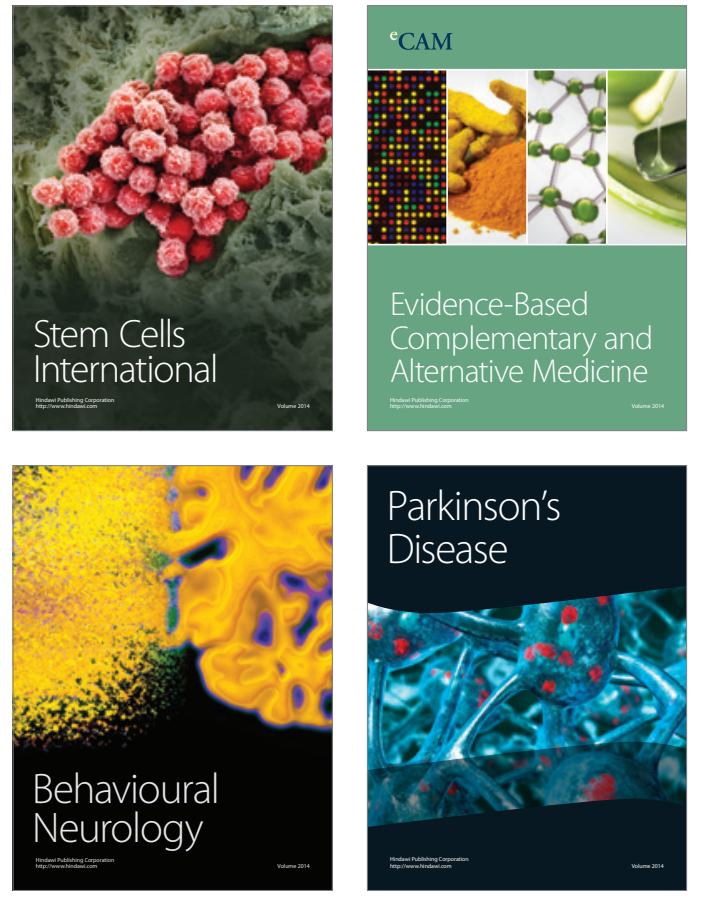
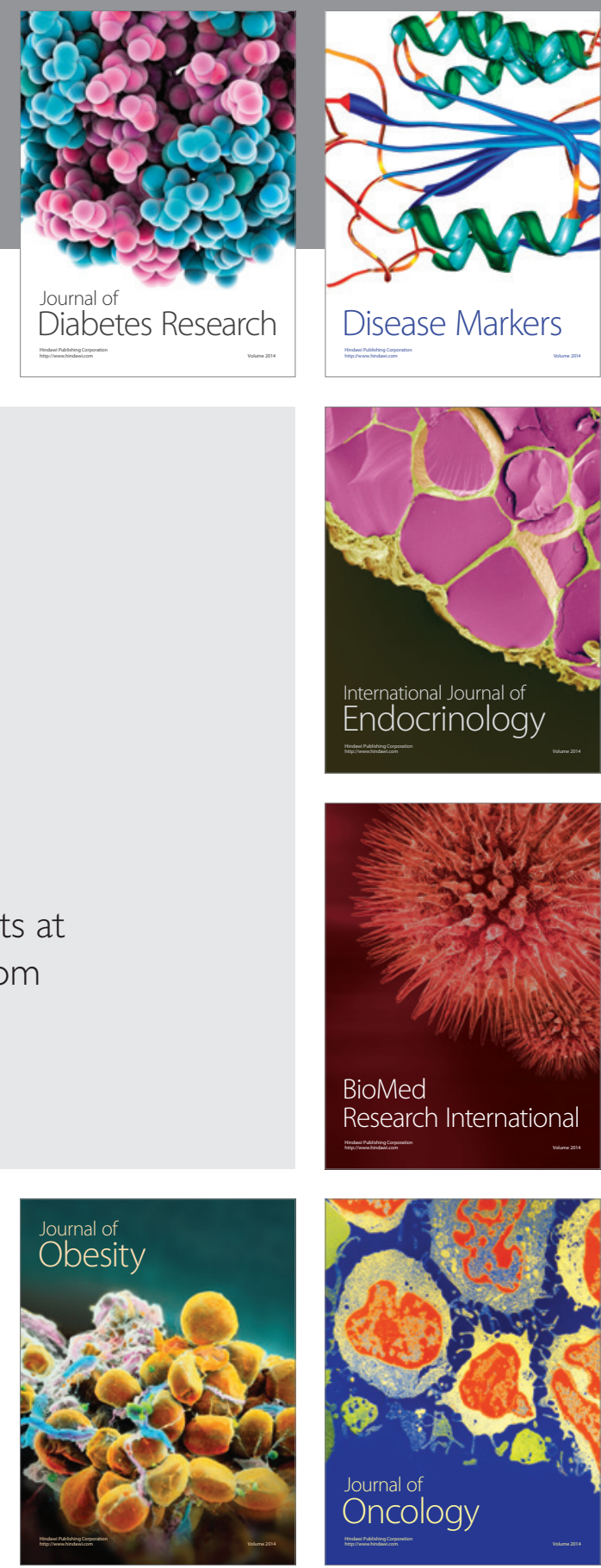

Disease Markers
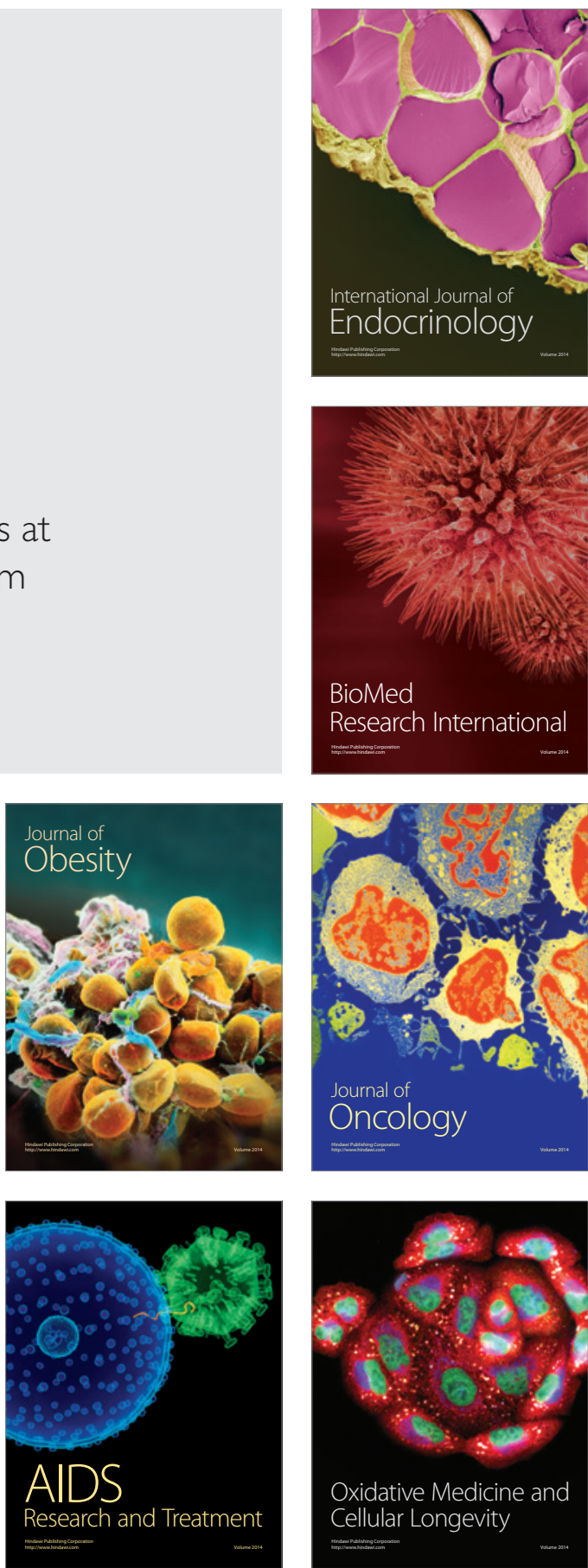